\title{
Penggunaan e-learning sebagai Pendukung Pelaksanaan Kurikulum 2013 pada SMAK St. Stanislaus Surabaya
}

\author{
Indra Budi Trisno \\ Program Studi Teknik Informatika \\ Universitas Widya Kartika \\ Surabaya, Indonesia \\ indrabt@gmail.com
}

\author{
Robby Kurniawan Budhi \\ Program Studi Teknik Informatika \\ Universitas Widya Kartika \\ Surabaya, Indonesia \\ robby@widyakartika.ac.id
}

\author{
Yonatan Widianto \\ Program Studi Teknik Informatika \\ Universitas Widya Kartika \\ Surabaya, Indonesia \\ yonatan@widyakartika.ac.id
}

\begin{abstract}
Kurikulum yang digunakan pada pendidikan sekolah menengah atas (SMA) saat ini adalah Kurikulum 2013. Perbedaan antara kurikulum saat ini dengan kurikulum sebelumnya adalah salah satunya dengan penyesuaian mata pelajaran. Salah satu mata pelajaran yang dihilangkan adalah Teknologi Informasi dan Komunikasi (TIK). Lebih lanjut dijelaskan bahwa TIK merupakan unsur pendukung yang mutlak digunakan dan terintegrasi pada setiap mata pelajaran yang diberikan. SMAK St. Stanislaus Surabaya mencoba mengaplikasikan hal tersebut dalam e-learning yang dibantu pelaksanaannya oleh Tim IbM Teknik Informatika Universitas Widya Kartika Surabaya.
\end{abstract}

Keywords—e-learning, kurikulum 2013

\section{PENDAHULUAN}

Menurut Kamus Besar Bahasa Indonesia, kata "kurikulum" memiliki arti "perangkat mata pelajaran yang diberikan pada lembaga pendidikan" [1]. Kurikulum yang digunakan pada pendidikan menengah saat ini adalah Kurikulum 2013. Secara umum, Kurikulum 2013 meliputi kelompok mata pelajaran wajib dan kelompok mata pelajaran peminatan sesuai bakat, minat, dan kemampuannya [2]. Kurikulum ini merupakan pengembangan dari kurikulum sebelumnya yaitu Kurikulum Tingkat Satuan Pendidikan (KTSP) tahun 2006. Salah satu perdebatan yang muncul dengan adanya perubahan kurikulum ini adalah hilangnya mata pelajaran Teknologi Informasi dan Komunikasi (TIK) / Ketrampilan Komputer dan Pengelolaan Informasi (KKPI). Pada kurikulum 2013, TIK diharapkan terintegrasi dengan mata pelajaran yang lain. Hal ini berlandaskan pemikiran bahwa TIK adalah sebagai alat bantu pembelajaran, bukan sebagai sesuatu yang harus diajarkan. Oleh karena itu, guru dituntut untuk lebih inovatif dan mampu membuat bahan pembelajaran yang berbasis TIK.

E-learning secara umum dapat diartikan sebagai penggunaan media elektronik untuk kegiatan komunikasi, pendidikan, dan pelatihan. Hal ini seperti yang disebutkan oleh The American Society for Training and Development (ASTD) dalam situs webnya about-elearning.com [3]. Melalui definisi yang disebutkan, e-learning merupakan proses dan kegiatan penerapan pembelajaran berbasis web (web-based learning), pembelajaran berbasis komputer (computer based learning), pendidikan virtual (virtual education) dan/atau kolaborasi digital (digital collaboration). Salah satu aplikasi $e$ learning yang telah dikenal adalah Moodle.

Saat ini, Moodle memiliki fasilitas untuk dapat dijalankan secara online tanpa instalasi tambahan terlebih dahulu. Melalui fasilitas ini, sumber daya peralatan yang dibitihkan tidak harus memiliki spesifikasi yang tinggi. Hal inilah yang dipandang sesuai dengan kondisi pada SMAK St. Stanislaus Surabaya. Pihak sekolah berpandangan bahwa penggunaan aplikasi e-learning sangat sesuai dengan penerapan kurikulum 2013. Namun saat ini, pihak sekolah kurang memiliki sumber daya manusia yang mampu menerapkan aplikasi ini. Masalah inilah yang dicoba untuk diselesaikan oleh Tim penerima hibah IPTEKS bagi Masyarakat dari Program Studi Teknik Informatika Universitas Widya Kartika Surabaya.

\section{METODE PELAKSANAAN}

\section{A. Studi Kelayakan}

Tahap pertama yang dilakukan adalah melakukan survey awal terhadap kelompok mitra yang membutuhkan. Hal ini dilakukan agar tindakan yang dilakukan tidak salah sasaran dan sesuai dengan kebutuhan. Survey dilakukan melalui wawancara, kuesioner pre test, dan koordinasi dengan sekolah mitra untuk menentukan pokok permasalahan dari situasi yang dihadapi.

Berdasarkan survey, diketahui bahwa dalam menghadapi persaingan dengan sekolah-sekolah yang lain, pihak sekolah merasa perlu meningkatkan fasilitas serta mutu pelayanan terhadap siswanya. Pihak sekolah melihat bahwa di sekolah lain, terdapat fasilitas e-learning yang dapat dimanfaatkan oleh siswa dan guru sebagai alat bantu pembelajaran. Melalui fasilitas itu pula, sekolah tersebut mampu mendapatkan penghargaan dan terbantu dalam hal publikasi. Sehingga, secara tidak langsung, dapat meningkatkan jumlah siswa yang berminat untuk masuk. 


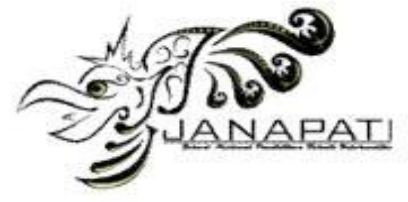

Selain itu, seiring dengan penggunaan kurikulum 2013, pihak sekolah ingin mengintegrasikan penggunaan teknologi informasi dalam proses belajar mengajar. Sedangkan guruguru sekolah belum semuanya menguasai penggunaan $e$ learning padahal dilihat dari sarana prasarana yang dimiliki, sekolah sebenarnya mampu menyediakan.

\section{B. Analisa Masalah}

Berdasarkan hasil pengamatan, Tim melakukan analisa situasi serta menetapkan langkah apa yang harus dilakukan untuk menyelesaikan masalah yang ditemui pada tahap pertama. Tim menggunakan analisis pohon masalah sebagai alat bantu untuk merumuskan masalah utama yang dihadapi oleh pihak sekolah.

Permasalahan utama yang dihadapi adalah rendahnya tingkat kemampuan guru dalam penguasaan e-learning sebagai alat bantu penerapan kurikulum 2013. Akibatnya, (1) penggunaan sarana prasarana kurang optimal, dan (2) proses pembelajaran masih bersifat konvensional melalui tatap muka di kelas. Penyebab dari masalah ini adalah (1) kurangnya kemampuan guru dalam penguasaan teknologi informasi, serta (2) penerapan kurikulum 2013 untuk sekolah yang sifatnya masih baru. Sebagai penyebab level kedua adalah (1) kurangnya pengalaman guru dalam menggunakan teknologi informasi, serta (2) latar belakang pendidikan guru yang berbeda-beda.

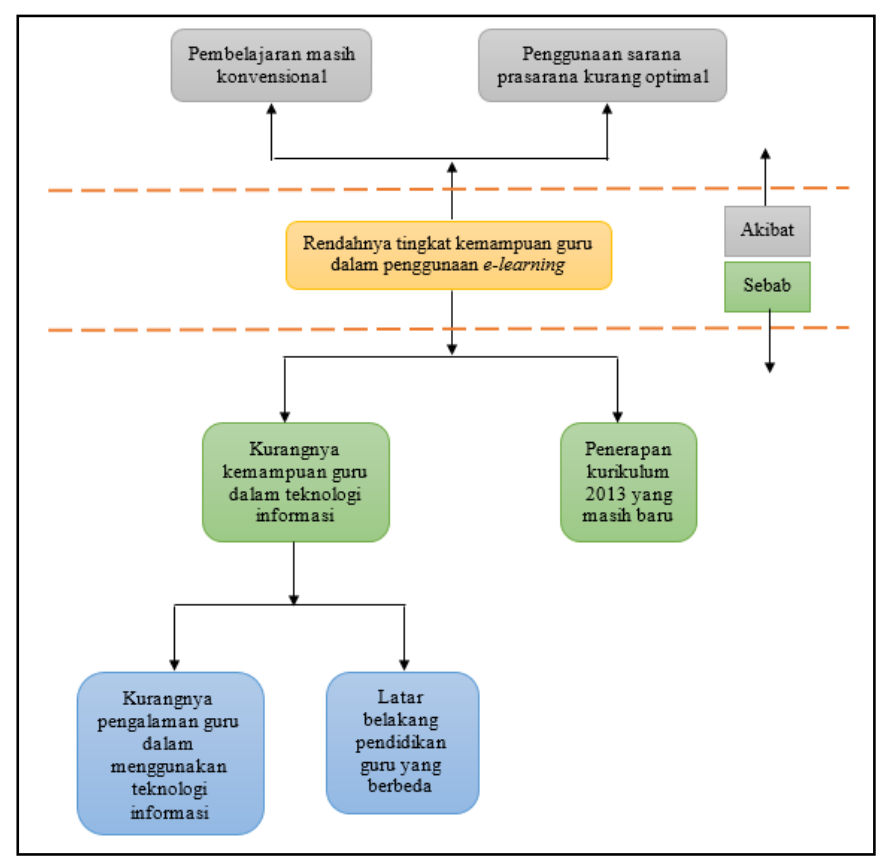

Gbr. 1. Pohon Masalah

\section{Perancangan Kegiatan}

Setelah melakukan analisa, dilakukan perencanaan kegiatan yang meliputi penentuan waktu, tempat, biaya, serta
ISSN 2089-8673

Jurnal Nasional Pendidikan Teknik Informatika (JANAPATI)

Volume 3, Nomor 3, Desember 2014

aplikasi apa yang akan digunakan. Penentuan waktu disesuaikan dengan waktu yang disediakan oleh pihak sekolah yaitu pada saat pertengahan bulan Juli, pada saat guru-guru mengikuti lokakarya dari sekolah. Tempat pelaksanaan kegiatan disepakati menggunakan laboratorium komputer milik sekolah, sedangkan aplikasi yang digunakan adalah Moodle.

\section{Implementasi Kegiatan}

Pada kasus yang dihadapi ini, Tim melakukan pelatihan terhadap guru-guru SMAK St. Stanislaus sebagai tahap awal. Tahap pertama adalah pelatihan bagi staf guru TIK yang sekaligus bertindak sebagai kepala laboratorium komputer. Tahap berikutnya adalah pelatihan bagi guru-guru. Untuk berikutnya, direncanakan adanya pelatihan bagi siswa.

\section{E. Evaluasi Kegiatan}

Setelah pelaksanaan kegiatan pelatihan, Tim melakukan evaluasi menggunakan kuesioner post-test sebagai umpan balik dari peserta kegiatan. Melalui kuesioner ini, Tim mengukur kemampuan guru setelah mengikuti pelatihan.

\section{F. Pendampingan}

Pada tahap ini diberikan pendampingan terhadap guru dan siswa oleh Tim dalam penggunaan aplikasi yang telah diberikan.

\section{Hasil Kegiatan}

Berdasarkan pengamatan awal, didapatkan data bahwa SMAK St. Stanislaus Surabaya memiliki dua kelas X, tiga kelas XI, dan tiga kelas XII dengan jumlah siswa \pm 250 siswa. Jumlah guru mata pelajaran adalah 17 orang. Sarana dan prasarana yang dimiliki cukup memadai yaitu adanya fasilitas internet seta wifi di lingkungan sekolah. Sekolah memiliki satu laboratorium komputer dengan kapasitas 40 siswa, dan bertindak sebagai penanggung jawab laboratorium adalah seorang guru TIK.

Pihak sekolah melakukan proses belajar mengajar melalui tatap muka di kelas. Namun pihak sekolah menginginkan pengembangan sarana pembelajaran agar siswa serta guru mampu berinteraksi dan memiliki alat bantu proses belajar mengajar yang lain selain tatap muka. Oleh karena itu, dipilihlah aplikasi e-learning. Karena keterbatasan server komputer yang dimiliki, maka disepakati penggunaan aplikasi Moodle secara online. Tampilan aplikasi ini dapat dilihat pada Gambar 1 [4]. 


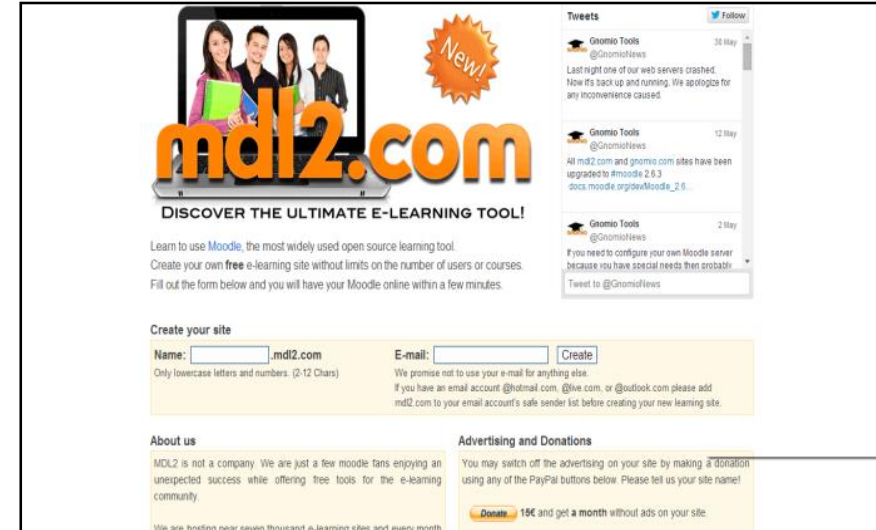

Gbr. 2. Tampilan Website Moodle Online

Pada saat pengamatan dilakukan, didapatkan data juga bahwa guru-guru belum mampu menggunakan aplikasi Moodle. Oleh karena itu, Tim merencanakan suatu kegiatan pelatihan bagi guru-guru. Pelatihan ini juga termasuk pelatihan Admin bagi guru TIK sebagai penanggung jawab laboratorium komputer.

\section{A. Pelatihan Admin}

Materi yang diberikan dalam pelatihan bagi Admin adalah

- Instalasi dan Konfigurasi Moodle Online. Hal ini menjelaskan tentang konfigurasi aplikasi Moodle yang akan digunakan.

- Manajemen User. Termasuk dalam bagian ini adalah pendafaran user yang akan menggunakan aplikasi Moodle.

- Membuat Kategori dan Kelas. Bagian ini menjelaskan pengelompokan user ke dalam kelas tertentu.

\section{B. Pelatihan Guru}

Materi yang diberikan dalam pelatihan bagi guru adalah :

- Menyiapkan Materi Ajar. Tahapan ini akan menjelaskan cara pembuatan materi ajar serta cara upload materi ajar.

- Forum Diskusi. Membahas penggunaan forum diskusi sebagai sarana interaksi antara guru dan siswa.

- Pengiriman dan Penilaian Tugas. Membahas manajemen pemberian tugas oleh guru serta pengumpulan tugas oleh siswa beserta penilaiannya.

- Pengelolaan Quiz. Membahas tentang evaluasi yang bisa diberikan oleh guru sebagai Ujian untuk siswa hingga pemberian nilainya.

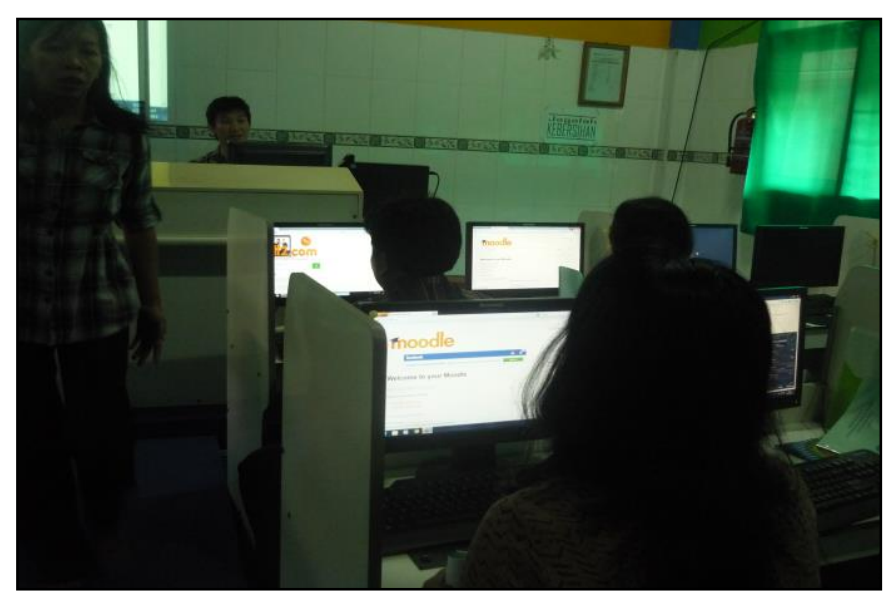

Gbr. 3. Pelatihan Moodle bagi Guru-guru SMAK St. Stanislaus

Pada saat pelatihan guru dilakukan, peserta yang mengikuti adalah 10 orang. Hal ini disebabkan adanya kesibukan beberapa guru yang pada saat itu juga menjalankan tugas mengikuti pelatihan di tempat lain. Suasana pelatihan dapat dilihat pada Gambar 2.

Sebagai sarana evaluasi, Tim melakukan pre-test dan posttest berupa kuesioner terhadap guru-guru. Selain itu, guru juga diminta mendemonstrasikan hasil pekerjaannya ketika diberikan soal tertentu oleh Tim.

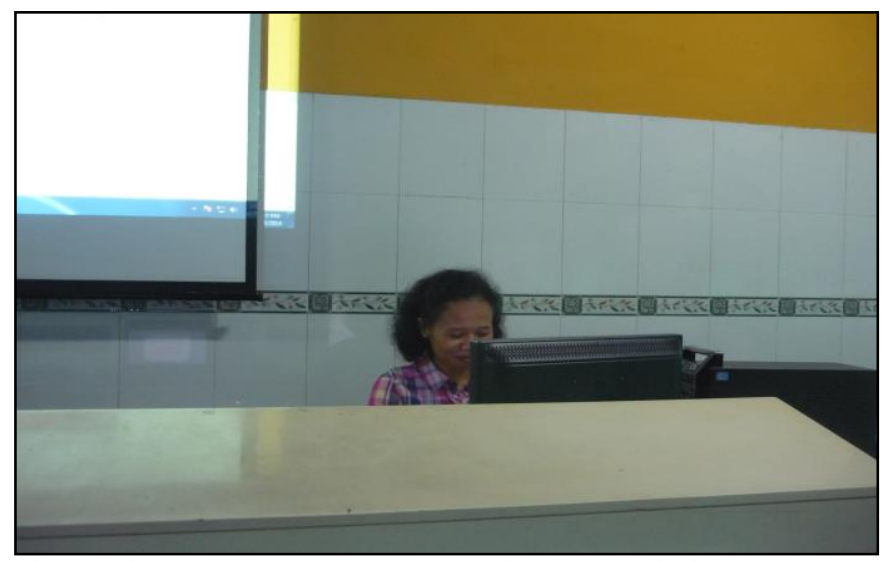

Gbr. 4. Salah Seorang Guru Mendemonstrasikan Hasil Pekerjaannya

Melalui pengamatan yang dilakukan pada saat pelaksanaan kegiatan pelatihan, perlu diadakan beberapa kali pelatihan bagi guru. Hal ini dimaksudkan agar guru tidak mudah lupa terhadap pelatihan yang sudah diterima. Selain itu, pihak guru memang membutuhkan waktu untuk memasukkan konten $e$ learning ke dalam aplikasi terlebih dahulu.

Sebagai tindak lanjut dari pelatihan guru ini, Tim juga merencanakan pelatihan bagi siswa serta pendampingan yang berkelanjutan bagi pihak sekolah secara umum. 
ISSN 2089-8673

Jurnal Nasional Pendidikan Teknik Informatika (JANAPATI)

Volume 3, Nomor 3, Desember 2014

\section{Pembahasan}

Melalui kegiatan yang telah dilaksanakan oleh Tim, didapatkan beberapa fakta yang berkaitan dengan pelaksanaan kurikulum 2013. Salah satunya adalah bahwa kesiapan guru dalam melaksanakan pengintegrasian TIK dalam mata pelajaran masih perlu ditingkatkan. Cara yang dapat ditempuh adalah salah satunya dengan melakukan kerjasama dengan pihak perguruan tinggi yang sesuai dengan kebutuhan. Hal ini perlu dilakukan karena titik berat proses pembelajaran yang diharapkan adalah kemampuan sumber daya manusia yang memadai dalam penguasaan TIK, bukan pelajaran mengenai TIK.

Berkaitan dengan hal ini, Tim memberikan evaluasi berupa kuesioner yang ditujukan kepada guru-guru SMAK St. Stanilaus sebagai mitra kerjasama pelatihan. Kuesioner ini salah satunya menilai kemampuan dasar guru dalam menjalankan suatu aplikasi e-learning. Guru-guru diminta memberikan penilaian terhadap kemampuan mereka dalam (1) membuat materi, (2) membuat forum diskusi, (3) mengelola tugas, dan (4) mengelola kuis atau ujian yang dapat dilakukan melalui aplikasi e-learning.

Hasilnya dapat dilihat pada tabel 1 bahwa kemampuan awal guru dalam menjalankan aplikasi e-learning masih sangat rendah. Hal ini menunjukkan bahwa e-learning masih merupakan suatu hal yang baru bagi para guru SMAK St. Stanislaus Surabaya. Data tersebut diperoleh melalui kuesioner pre-test sebelum kegiatan pelatihan dilakukan.

Setelah pelatihan, kembali diadakan evaluasi untuk mengetahui data yang sama dengan pre-test. Hasilnya, setelah melalui pelatihan, kemampuan guru dapat ditingkatkan hingga rata-rata $70 \%$ dalam penguasaan masing-masing materi. Hal ini menunjukkan bahwa pelatihan yang dilakukan cukup efektif.

Tabel 1. Perbandingan Pre-test dan Post-test Nilai Prosentase KEMAMPUAN GURU DALAM MENJALANKAN APLIKASI E-LEARNING

\begin{tabular}{|l|c|c|}
\hline \multirow{2}{*}{ Kemampuan Guru } & \multicolumn{2}{c|}{ Nilai Rerata } \\
\cline { 2 - 3 } & $\begin{array}{c}\text { Pre-test } \\
(\%)\end{array}$ & $\begin{array}{c}\text { Post-test } \\
(\%)\end{array}$ \\
\hline Membuat materi & 6 & 77.5 \\
\hline Mengunggah materi & 6 & 80 \\
\hline Membuat forum diskusi & 6 & 75 \\
\hline Membuat topik diskusi & 6 & 75 \\
\hline Membalas pesan dari diskusi & 6 & 72.5 \\
\hline Menambahkan tugas & 6 & 77.5 \\
\hline Memberikan komentar dan penilaian tugas & 4 & 70 \\
\hline Penilaian kegiatan offline & 6 & 65 \\
\hline Pembuatan quiz & 6 & 77.5 \\
\hline
\end{tabular}

\begin{tabular}{|l|c|c|}
\hline \multirow{2}{*}{ Kemampuan Guru } & \multicolumn{2}{|c|}{ Nilai Rerata } \\
\cline { 2 - 3 } & $\begin{array}{c}\text { Pre-test } \\
(\%)\end{array}$ & $\begin{array}{c}\text { Post-test } \\
(\%)\end{array}$ \\
\hline Pembuatan pertanyaan pilihan ganda dalam quiz & 6 & 77.5 \\
\hline Pembuatan pertanyaan essay dalam quiz & 4 & 78 \\
\hline Mengimpor pertanyaan ke dalam quiz & 4 & 75 \\
\hline
\end{tabular}

Berdasarkan kuesioner, didapatkan masukan dari guru mitra, bahwa diperlukan adanya pendampingan yang berkelanjutan tentang pemakaian aplikasi ini. Oleh karena itu, Tim juga merencanakan adanya pendampingan bagi guru serta siswa.

Melalui kegiatan ini, dapat diamati juga bahwa e-learning dapat menjadi cara yang efektif untuk mengintegrasikan TIK di dalam setiap mata pelajaran. Karena di sisi guru, guru telah menerapkan metode pembelajaran yang inovatif. Sedangkan di sisi siswa, siswa juga dapat meningkatkan kemampuannya menggunakan TIK dalam proses belajar mengajar.

\section{Kesimpulan}

Setelah pelaksanaan kegiatan yang dilakukan oleh Tim IbM Program Studi Teknik Informatika Universitas Widya Kartika Surabaya dan guru-guru SMAK St. Stanislaus Surabaya, dapat ditarik beberapa kesimpulan.

1) E-learning dapat digunakan sebagai pendukung pelaksanaan kurikulum 2013 di SMAK St. Stanislaus Surabaya.

2) E-learning merupakan salah satu cara pengintegrasian TIK dalam mata pelajaran pada kurikulum 2013.

3) Kegiatan pelatihan yang dilakukan, mampu membantu meningkatkan kemampuan sumber daya manusia dari SMAK St. Stanislaus Surabaya dalam kesiapannya menjalankan kurikulum 2013.

\section{Acknowledgment}

Secara khusus, Tim IbM Program Studi Teknik Informatika Universitas Widya Kartika Surabaya mengucapkan terima kasih kepada Kepala Sekolah dan guruguru dari SMAK St. Stanislaus Surabaya yang telah bekerjasama dengan baik. Semoga kegiatan yang telah terlaksana dapat berguna dan mempererat kerjasama antar institusi. Tim juga mengucapkan terima kasih kepada Ditjen Pendidikan Tinggi yang telah mendanai kegiatan ini. Tim juga mengucapkan terima kasih kepada Ketua LP3M Universitas Widya Kartika. 
ISSN 2089-8673

Jurnal Nasional Pendidikan Teknik Informatika (JANAPATI)

Volume 3, Nomor 3, Desember 2014

\section{Referensi}

[1] Pusat Bahasa. 2008. Kamus Besar Bahasa Indonesia Online. [Online]. Available : http://bahasa.kemdiknas.go.id/kbbi/index.php

[2] Kementrian Pendidikan dan Kebudayaan, "Kurikulum 2013 Kompetensi Dasar", 2013, p. 2.

[3] The American Society for Training and Development (ASTD). (2014). Definition of e-Learning. [Online]. Available : http://www.aboutelearning.com/definition-of-e-learning.html.

[4] MDL2. (2014). Online Moodle. [Online]. Available : http://www.mdl2.com. 